\title{
Copolymerization of Acrylonitrile with Vinyl Chloride Catalyzed by Ethylaluminum Chloride with or without Transition Metal Compounds
}

\author{
Junji Furukawa, Eiichi Kobayashi, ${ }^{*}$ and Junnosuke Yamauchi** \\ Department of Synthetic Chemistry, Kyoto University, Kyoto, Japan.
}

(Received February 5, 1971)

\begin{abstract}
Copolymerization of acrylonitrile with vinyl chloride catalyzed by ethylaluminum chloride with or without transition metal compounds was investigated. The copolymer composition was markedly influenced by the amount of ethylaluminum dichloride. The addition of transition metal compound enhances the yield of copolymer, but has no effect on copolymer composition. The alternating copolymer was produced only in the presence of an equimolar or more amount of ethylaluminum dichloride with respect to acrylonitrile. The acrylonitrile-rich copolymer is formed when a less amount of complexing agent is used and this fact is interpreted by the copolymerization between free acrylonitrile monomer and the ternary complex of aluminum compound -acrylonitrile-vinyl chloride.
\end{abstract}

KEY WORDS Copolymerization / Acrylonitrile / Vinyl Chloride / Alternating Copolymerization / Ethylaluminum Chloride / Transition Metal Compound / Vanadium / Cobalt / Mixing Order / Catalyst / Copolymer Composition / NMR / Copolymer / Copolymerization Mechanism /

Until recently there have been many reports on the polymerization and copolymerization of acrylic monomers in the presence of Lewis acids as complexing agents. ${ }^{1}$ Several authors have succeeded in the alternating copolymerization of acrylic monomers with $\alpha$-olefins ${ }^{2,3}$ and diolefins. ${ }^{4,5}$ The copolymer of acrylonitrile and vinylidene chloride prepared in the presence of zinc chloride reported by Imoto, et al., had a non-alternating structure, but the paten $\mathrm{t}^{6}$ claimed that the copolymer of acrylonitrile and vinyl chloride prepared in the presence of ethylaluminum dichloride had an alternating structure. The latter fact was confirmed recently by Pasynkiewicz, et al. ${ }^{7}$

This report deals with the detailed condition favorable to the formation of the alternating copolymer and elucidates the fact that the

* Institute for Chemical Research, Kyoto University, Uji, Japan.

** Institute for Chemical Research, Kyoto University, Uji, Japan. On leave from Central Research Laboratory, Kuraray Co., Ltd., Kurashiki, Okayama, Japan. alternating and non-alternating copolymers are formed depending upon the amount of ethylaluminum dichloride.

\section{EXPERIMENTAL}

Acrylonitrile(AN) was refluxed over Molecular Sieves $3 \mathrm{~A}$ for about $4 \mathrm{hr}$ and subsequently distilled before use. Vinyl chloride(VC) of polymerization grade was purified by passing through columns packed with potassium hydroxide pellets, calcium chloride, barium oxide, and Molecular Sieves 3A, followed by filtering off frozen water after cooling to $-78^{\circ} \mathrm{C}$ for about one day. Organoaluminum halides were distilled in vacuo before use. Transition metal compounds of chemically pure grade were used without further purification. Solvents were purified in the usual way.

Copolymerization was mainly carried out according to the following procedure. A dry glass ampoule was evacuated and flushed with pure nitrogen gas, and subsequently acrylonitrile and toluene were introduced into it. 


\section{J. Furukawa, E. Kobayashi, and J. Yamauchi}

The glass ampoule was dipped in a bath cooled at $-78^{\circ} \mathrm{C}$, and then ethylaluminum chloride was added slowly and the solution was mixed sufficiently. The liquid vinyl chloride monomer cooled at $-78^{\circ} \mathrm{C}$ was added with sufficient mixing. Finally the transition metal compound was added. The ampoule was sealed and dipped in a polymerization bath. After a given time, isopropanol was added to the reaction mixture which was subsequently poured into a large excess of methyl alcohol containing a small amount of hydrogen chloride. The coagulated polymer was washed with a large amount of methyl alcohol, dried in vacuo and then weighed. The copolymer was purified by pouring the acetone or dimethylformamide solution of copolymer into a large amount of methyl alcohol.

The copolymer composition was estimated from the content of nitrogen in copolymer determined by elementary analysis. Sometimes total analysis of $\mathrm{C}, \mathrm{H}, \mathrm{N}$, and $\mathrm{Cl}$ was carried out in order to examine the accuracy of the analysis. NMR spectrum of the copolymer was measured by $100-M c$ Varian NMR Spectrometer at $6-\%$ of polymer concentration and at $80^{\circ} \mathrm{C}$ by using $\left(\mathrm{CD}_{3}\right)_{2} \mathrm{SO}$ as a solvent and TMS as an internal standard.

\section{RESULTS AND DISCUSSIONS}

The copolymerization was investigated by the use of the catalyst containing various kinds of ethylaluminum chloride added to acrylonitrile monomer at $-78^{\circ} \mathrm{C}$ in a molar ratio of $1: 1$. As shown in Table I, ethylaluminum dichloride $\left(\mathrm{EtAlCl}_{2}\right)$ is the best catalyst giving a white alternating copolymer, whereas ethylaluminum sesquichloride $\left(\mathrm{Et}_{1.5} \mathrm{AlCl}_{1: 5}\right)$ or diethylaluminum monochloride $\left(\mathrm{Et}_{2} \mathrm{AlCl}\right)$ is scarcely active. This order of activity agreed with the order of acidity of the ethylaluminum chlorides. ${ }^{8}$ The acidity of the complexing agent may be very important in this copolymerization. The over-all rate of copolymerization of acrylonitrile with vinyl chloride by $\mathrm{EtAlCl}_{2}$ is lower than that of the copolymerization $^{2}$ of acrylonitrile with propylene. The activity by $\mathrm{Et}_{1.5} \mathrm{AlCl}_{1.5}$ and $\mathrm{Et}_{2} \mathrm{AlCl}$ in acrylonitrile-vinyl chloride copolymerization is very low, contrary to the high activity in acrylonitrile-propylene ${ }^{2}$ and acrylonitrilebutadiene. $^{4}$

As $\mathrm{EtAlCl}_{2}$ is the best complexing agent and catalyst, the copolymerization was thereinafter investigated with $\mathrm{EtAlCl}_{2}$.

The mixing order of the catalyst components was especially important in the copolymerization of acrylonitrile with vinyl chloride, because vinyl chloride is reactive with $\mathrm{EtAlCl}_{2}$ in the

Table I. Alternating copolymerization of acrylonitrile with vinyl chloride by various kinds of ethylaluminum chloride at $-78^{\circ} \mathrm{C}^{\mathrm{a}}$

\begin{tabular}{|c|c|c|c|c|c|c|c|c|}
\hline \multicolumn{3}{|c|}{ Feed monomer } & \multirow{2}{*}{$\begin{array}{c}\text { Al- } \\
\text { Compounds }\end{array}$} & \multirow{2}{*}{$\underset{\substack{\text { molar } \\
\text { ratio }}}{\text { Al/AN, }}$} & \multirow{2}{*}{$\begin{array}{l}\text { Poly- } \\
\text { merization } \\
\text { time, } \\
\text { day }\end{array}$} & \multirow{2}{*}{$\begin{array}{l}\text { Polymer, } \\
\text { g }\end{array}$} & \multirow{2}{*}{$\begin{array}{c}\text { Conver- } \\
\text { sionb } \\
\%\end{array}$} & \multirow{2}{*}{$\begin{array}{c}\mathrm{AN} \\
\text { content in } \\
\text { polymer, } \\
\text { mol } \%\end{array}$} \\
\hline $\begin{array}{l}\text { AN, } \\
\text { mmol }\end{array}$ & $\begin{array}{l}\mathrm{VC}, \\
\mathrm{mmol}\end{array}$ & $\begin{array}{c}\mathrm{AN} /(\mathrm{AN}+\mathrm{VC}) \\
\mathrm{mol} \%\end{array}$ & & & & & & \\
\hline 50 & 50 & 50 & $\mathrm{Et}_{2} \mathrm{AlCl}$ & 1.1 & 14 & trace & - & - \\
\hline 40 & 12 & 76.5 & $\mathrm{Et}_{1.5} \mathrm{AlCl}_{1.5}$ & 1.1 & 14 & $0.03_{1}$ & 2.2 & 51 \\
\hline 50 & 50 & 50 & $\mathrm{Et}_{1.5} \mathrm{AlCl}_{1.5}$ & 1.1 & 14 & $0.03_{9}$ & 0.7 & 52 \\
\hline 40 & 160 & 20 & $\mathrm{Et}_{1.5} \mathrm{AlCl}_{1.5}$ & 1.1 & 14 & $0.11_{1}$ & 2.4 & 50 \\
\hline 30 & 10 & 75 & $\mathrm{EtAlCl}_{2}{ }^{\mathrm{c}}$ & 1.1 & $6 \mathrm{hr}$ & $0.12_{2}$ & 10.6 & 52 \\
\hline 20 & 20 & 50 & $\mathrm{EtAlCl}{ }_{2}^{\mathrm{c}}$ & 1.1 & $6 \mathrm{hr}$ & $0.97_{2^{d}}$ & 42.0 & 50 \\
\hline 10 & 30 & 25 & $\mathrm{EtAlCl}_{2}{ }^{\mathrm{c}}$ & 1.1 & $6 \mathrm{hr}$ & $0.20_{1}$ & 17.5 & 50 \\
\hline $\begin{array}{l}{ }^{\text {a }} \text { Catal } \\
{ }^{\mathrm{b}} \text { Weig } \\
\text { c Used } \\
\text { d }[\eta]=1\end{array}$ & $\begin{array}{l}\text { was us } \\
\mathrm{Po} \\
\text { of AN- } \\
\text { toluene } \\
\mathrm{d} / \mathrm{g}), \mathrm{m}\end{array}$ & $\begin{array}{l}\text { ed as toluene sol } \\
\text { ymer } \\
\text {-VC(1:1) comple } \\
\text { solution of } 5 \mathrm{mo} \\
\text { easured in aceton }\end{array}$ & $\begin{array}{l}\text { ation of } 2 \mathrm{~mol} \\
-\times 100 \text {. }\end{array}$ & & & & & \\
\hline
\end{tabular}


Copolymerization of Acrylonitrile with Vinyl Chloride

Table II. The effect of the mixing order on AN-VC copolymerization ${ }^{\mathrm{a}}$

\begin{tabular}{|c|c|c|c|c|c|c|}
\hline \multirow{2}{*}{$\begin{array}{l}\text { Mixing } \\
\text { order }\end{array}$} & \multicolumn{3}{|c|}{ Monomer } & \multirow{2}{*}{$\begin{array}{c}\mathrm{EtAlCl}_{2}^{\mathrm{b}}, \\
\mathrm{mmol}\end{array}$} & \multirow{2}{*}{$\underset{\mathrm{g}}{\text { Polymer, }}$} & \multirow{2}{*}{$\begin{array}{c}\text { Conversion } \\
\%\end{array}$} \\
\hline & $\begin{array}{l}\mathrm{AN}, \\
\mathrm{mmol}\end{array}$ & $\begin{array}{l}\mathrm{VC}, \\
\mathrm{mmol}\end{array}$ & $\underset{\mathrm{AN} /(\mathrm{AN}+\mathrm{VC})}{\mathrm{mol} \%}$ & & & \\
\hline $\mathrm{AN} \rightarrow \mathrm{A} 1 \rightarrow \mathrm{VC}$ & 37.5 & 112.5 & 25 & 37.5 & $0.19_{3}$ & 4.5 \\
\hline $\mathrm{AN} \rightarrow \mathrm{Al} \rightarrow \mathrm{VC}$ & 75.0 & 75.0 & 50 & 37.5 & $0.34_{9}$ & 8.1 \\
\hline $\mathrm{AN} \rightarrow \mathrm{VC} \rightarrow \mathrm{A} 1$ & 37.5 & 112.5 & 25 & 37.5 & $0.02_{1}$ & 0.5 \\
\hline $\mathrm{AN} \rightarrow \mathrm{VC} \rightarrow \mathrm{A} 1$ & 75.0 & 75.0 & 50 & 37.5 & $0.01_{6}$ & 0.4 \\
\hline $\mathrm{AN} \rightarrow \mathrm{VC} \rightarrow \mathrm{Al}$ & 112.5 & 37.5 & 75 & 37.5 & $0.03_{3}$ & 0.8 \\
\hline
\end{tabular}

a Polymerization conditions: toluene, $8 \mathrm{~m} l$; temperature, $-78^{\circ} \mathrm{C}$; time, $16 \mathrm{hr}$.

b Used as toluene solution of $4.7 \mathrm{~mol} / l$.

absence of suitable complexing agents with $\mathrm{EtAlCl}_{2}$. In fact, when $\mathrm{EtAlCl}_{2}$ was introduced directly to vinyl chloride, violent reaction occurred and the solution colored brownish, but polymerization did not proceed. When $\mathrm{EtAlCl}_{2}$ was added to the mixture of acrylonitrile and vinyl chloride, the reaction solution was colored brownish and polymerization scarcely proceeded, even in the presence of excess of acrylonitrile. In these cases, Friedel-Crafts reaction occurred between vinyl chloride and toluene. ${ }^{9}$ The reaction of $\mathrm{EtAlCl}_{2}$ with vinyl chloride is faster than that with acrylonitrile. It may be necessary that $\mathrm{EtAlCl}_{2}$ is mixed and complexed with acrylonitrile prior to contact directly with vinyl chloride. Table II summarizes the effect of the mixing order.

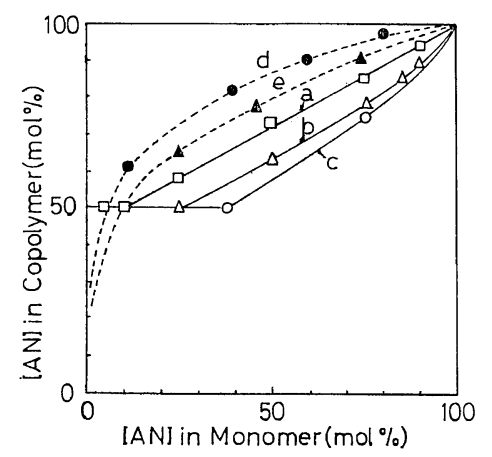

Figure 1. Copolymer composition curves: $[\mathrm{AN}+$ VC], $200 \mathrm{mmol} ; 2 \mathrm{ml}$ of toluene; temp, $-78^{\circ} \mathrm{C}$. $\left[\mathrm{EtAlCl}{ }_{2}\right] /[\mathrm{AN}+\mathrm{VC}]$ in molar ratio: a, $0.05 ; \mathrm{b}$, $0.25 ; \mathrm{c}, 0.38$.

Conventional free radical copolymerization: d, $-25^{\circ} \mathrm{C}$, redox catalyst; $1^{10} \mathrm{e}, 60^{\circ} \mathrm{C}$, benzoylperoxide catalyst.
In the vinyl chloride-acrylonitrile copolymerization, the copolymer composition is much affected by the amount of EtAlCl ${ }_{2}$ in contrast with the butadiene-acrylonitrile copolymerization. The latter system yields always the $1: 1$ copolymer independent of the amount of $\mathrm{EtAlCl}_{2}$, whereas the former one affords random copolymers when the amount of $\mathrm{EtAlCl}_{2}$ is smaller than that of AN monomer. The alternating copolymer is obtainable only when an equimolar or more amount of $\mathrm{EtAlCl}_{2}$ to acrylonitrile is used.

Figures 1 and 2 illustrate that the copolymer composition is remarkably influenced by the $\mathrm{Al} / \mathrm{AN}$ ratio. In Figure 1 the amount of EtAlCl ${ }_{2}$ is kept constant with respect to total monomer and in Figure 2 to that of $\mathrm{AN}$ monomer. In both cases, the AN content in the polymer is higher than $50 \%$ depending on

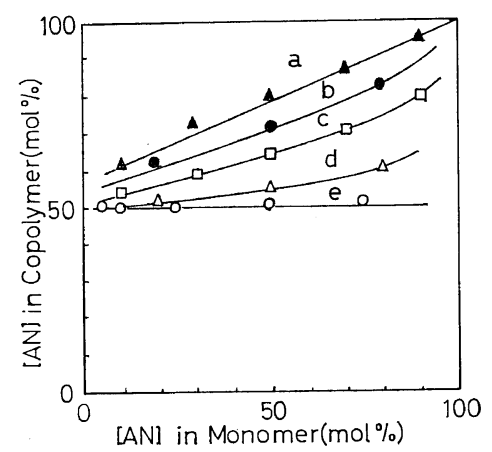

Figure 2. Copolymer composition curves.

$\mathrm{EtAlCl}_{2}$ is used as toluene solution of $4.7 \mathrm{~mol} / l$; temp, $-78^{\circ} \mathrm{C}$.

[EtAlCl $] /[\mathrm{AN}]$ in molar ratio: a, $0.10 ; \mathrm{b}, 0.30$; c, 0.50; d, 0.75; e, 1.1 . 
Table III. Alternating copolymerization by $\mathrm{EtAlCl}_{2}$ at various temperatures ${ }^{\mathrm{a}}$

\begin{tabular}{|c|c|c|c|c|c|c|c|c|}
\hline \multicolumn{3}{|c|}{ Feed Monomer } & \multirow{2}{*}{$\begin{array}{l}\mathrm{EtAlCl}_{2}, \\
\mathrm{mmol}\end{array}$} & \multirow{2}{*}{$\begin{array}{c}\text { Poly- } \\
\text { merization } \\
\text { temp, } \\
{ }^{\circ} \mathrm{C}\end{array}$} & \multirow{2}{*}{$\begin{array}{c}\text { Poly- } \\
\text { merization } \\
\text { time, } \\
\text { hr }\end{array}$} & \multirow{2}{*}{$\begin{array}{l}\text { Polymer, } \\
\mathrm{g}\end{array}$} & \multirow{2}{*}{$\begin{array}{c}\text { Conver- } \\
\text { sion, } \\
\%\end{array}$} & \multirow{2}{*}{$\begin{array}{c}\text { AN } \\
\text { content in } \\
\text { polymer, } \\
\text { mol } \%\end{array}$} \\
\hline $\begin{array}{l}\mathrm{AN}, \\
\mathrm{mmol}\end{array}$ & $\begin{array}{l}\mathrm{VC}, \\
\mathrm{mmol}\end{array}$ & $\begin{array}{c}\mathrm{AN} /(\mathrm{AN}+\mathrm{VC}) \\
\mathrm{mol} \%\end{array}$ & & & & & & \\
\hline 40 & 10 & 80 & 44 & 0 & 72 & $0.70_{6}$ & 86.5 & 49 \\
\hline 25 & 25 & 50 & 27 & 0 & 5 & $0.32_{4}$ & 11.3 & 50 \\
\hline 30 & 70 & 30 & 32 & 0 & 5 & $0.52_{0}$ & 15.0 & 50 \\
\hline 20 & 180 & 10 & 22 & 0 & 5 & $0.15_{1}$ & 6.5 & 49 \\
\hline 40 & 10 & 80 & 44 & -30 & 72 & $0.53_{4}$ & 61.7 & 51 \\
\hline 25 & 25 & 50 & 27 & -30 & 5 & $0.68_{4}$ & 23.7 & 50 \\
\hline 30 & 70 & 30 & 32 & -30 & 5 & 0.65 & 18.8 & 50 \\
\hline 20 & 180 & 10 & 22 & -30 & 5 & $0.18_{5}$ & 8.0 & 49 \\
\hline 30 & 10 & 75 & $33^{b}$ & -78 & 6 & $0.12_{2}$ & 10.6 & 52 \\
\hline 20 & 20 & 50 & $22^{b}$ & -78 & 6 & $0.97_{2}$ & 42.0 & 50 \\
\hline 10 & 30 & 25 & $11^{\mathrm{b}}$ & -78 & 6 & $0.20_{1}$ & 17.5 & 50 \\
\hline 10 & 90 & 10 & $11^{\mathrm{b}}$ & -78 & 6 & $0.15_{6}$ & 13.5 & 50 \\
\hline 10 & 190 & 5 & $11^{\mathrm{b}}$ & -78 & 6 & $0.06_{8}$ & 5.9 & 50 \\
\hline
\end{tabular}

a Catalyst was used as toluene solution of $2 \mathrm{~mol} / \mathrm{l}$.

b Used as toluene solution of $5 \mathrm{~mol} / l$.

the monomer composition. With an increasing amount of alkylaluminum chloride, the deviation of $\mathrm{AN}$ content from $50 \%$ is diminished and the use of an equimolar amount of $\mathrm{EtAlCl}_{2}$ with respect to $\mathrm{AN}$ monomer enables the formation of the 1:1-copolymer irrespective of the feed monomer composition. More or slightly more than an equimolar amount of $\mathrm{EtAlCl} \mathrm{A}_{2}$ is used in the experiment for the sake of elimination of the effect of impurities in the solution, such as water and oxygen. As illustrated above, it was found that the copolymer composition is affected not only by the feed monomer composition but also by the amount of $\mathrm{EtAlCl}_{2}$ added to acrylonitrile, unlike the ordinary alternating copolymerization.

When an equimolar amount of $\mathrm{EtAlCl}_{2}$ is used with respect to $\mathrm{AN}$ monomer, the alternating copolymerization occurs even at a low temperature of $-78^{\circ} \mathrm{C}$ as shown in Table III. The dependency of the rate of polymerization on the polymerization temperature seems to be very small. Above room temperature the reaction system tends to color yellowish during long polymerization, although the alternating copolymerization still takes place.

Another influential factor on polymerization is a cocatalyst such as $\mathrm{VOCl}_{3}$. In the copoly- merization of acrylonitrile with butadiene, an alternating copolymer was obtained by using a small amount of $\mathrm{EtAlCl}_{2}-\mathrm{VOCl}_{3}$ catalyst systems, ${ }^{4}$ and the addition of $\mathrm{VOCl}_{3}$ as cocatalyst effectuates the regeneration of the organoaluminum halide. ${ }^{11}$ In the copolymerization of acrylonitrile with vinyl chloride, $\mathrm{VOCl}_{3}$ also remarkably accelerates the polymerization.

In the presence of an equimolar or more amount of $\mathrm{EtAlCl}_{2}$ with respect to $\mathrm{AN}$ monomer, the alternating copolymerization proceeds more effectively with the addition of small amounts of $\mathrm{VOCl}_{3}$ than without. The results are shown in Table IV. The results of copolymerization at $-78^{\circ} \mathrm{C}$ and $-30^{\circ} \mathrm{C}$ are described in Tables $\mathrm{V}$ and VI. The copolymer composition curves with or without $\mathrm{VOCl}_{3}$ are shown in Figure 3.

Other transition metal compounds, such as $\mathrm{Co}(\mathrm{acac})_{3}, \quad \mathrm{~V}(\mathrm{acac})_{3}$, a $1: 1$-mixture of $\mathrm{TiCl}_{4}$ and $\mathrm{Ti}\left(\mathrm{OC}_{4} \mathrm{H}_{9}\right)_{4}$, and $\mathrm{VO}\left(\mathrm{OC}_{2} \mathrm{H}_{5}\right)_{3}$ accelerate the polymerization effectively, but all of them have no effect on copolymer composition as illustrated in Table VII.

The copolymer produced by an equimolar or more amount of aluminum compound with respect to AN monomer is assumed to be alter- 
Copolymerization of Acrylonitrile with Vinyl Chloride

Table IV. Alternating copolymerization by $\mathrm{EtAlCl}_{2}-\mathrm{VOCl}_{3}$ catalyst system

\begin{tabular}{|c|c|c|c|c|c|c|c|c|c|}
\hline \multicolumn{3}{|c|}{ Feed monomer } & \multirow{2}{*}{$\begin{array}{c}\mathrm{EtAlCl}_{2}{ }^{\mathrm{a}} \\
/ \mathrm{AN}, \\
\text { molar } \\
\text { ratio }\end{array}$} & \multirow{2}{*}{$\begin{array}{c}\mathrm{VOCl}_{3}{ }^{\mathrm{b}} \\
\text { motAlCl}_{2} \\
\text { molar } \\
\text { ratio }\end{array}$} & \multirow{2}{*}{$\begin{array}{l}\text { Poly- } \\
\text { merization } \\
\text { temp, } \\
{ }^{\circ} \mathrm{C}\end{array}$} & \multirow{2}{*}{$\begin{array}{c}\text { Poly- } \\
\text { merization } \\
\text { time, } \\
\text { hr }\end{array}$} & \multirow{2}{*}{$\underset{\mathrm{g}}{\text { Polymer, }}$} & \multirow{2}{*}{$\begin{array}{c}\text { Conver- } \\
\text { sion, } \\
\%\end{array}$} & \multirow{2}{*}{$\begin{array}{c}\text { AN } \\
\text { content in } \\
\text { polymer, } \\
\text { mol } \%\end{array}$} \\
\hline $\begin{array}{l}\text { AN, } \\
\text { mmol }\end{array}$ & $\begin{array}{l}\mathrm{VC} \\
\mathrm{mmol}\end{array}$ & $\begin{array}{c}\mathrm{AN} /(\mathrm{AN}+\mathrm{VC}) \\
\mathrm{mol} \%\end{array}$ & & & & & & & \\
\hline 40 & 12 & 76.5 & 1.1 & 0.1 & -78 & 4 & $0.34_{8}$ & 25.0 & 50 \\
\hline 50 & 50 & 50 & 1.04 & 0.1 & -78 & 4 & $1.39_{2}$ & 24.2 & 51 \\
\hline 40 & 160 & 20 & 1.1 & 0.1 & -78 & 4 & $1.00_{9}$ & 21.8 & 50 \\
\hline 50 & 12.5 & 80 & 1.1 & 0.0014 & -78 & 18 & $0.34_{9} \mathrm{c}$ & 24.1 & 52 \\
\hline 60 & 60 & 50 & 1.1 & 0.0014 & -78 & 18 & $0.828^{\mathrm{d}}$ & 12.0 & 52.5 \\
\hline 40 & 12 & 76.5 & 1.1 & 0.1 & -30 & 3 & $0.39_{8}$ & 29.8 & 50 \\
\hline 50 & 50 & 50 & 1.04 & 0.1 & -30 & 3 & $2.85_{1}$ & 49.5 & 49 \\
\hline 40 & 10 & 80 & 1.1 & 0.0014 & -30 & 17 & $0.77_{9}$ & 67.5 & 50 \\
\hline 50 & 50 & 50 & 1.1 & 0.0014 & -30 & 1 & $1.22_{8}$ & 21.3 & 50 \\
\hline 40 & 160 & 20 & 1.1 & 0.0014 & -30 & 1 & $1.98^{\mathrm{e}}$ & 43.0 & 49 \\
\hline 40 & 10 & 80 & 1.1 & $6 \times 10^{-4}$ & 0 & 0.43 & $0.51_{1}$ & 44.2 & 52.5 \\
\hline 50 & 50 & 50 & 1.1 & $6 \times 10^{-4}$ & 0 & 0.17 & $3.09_{1}$ & 53.5 & 49 \\
\hline 40 & 160 & 20 & 1.1 & $6 \times 10^{-4}$ & 0 & 0.17 & $2.51_{6} \mathrm{f}$ & 54.5 & 49 \\
\hline
\end{tabular}

a Used as toluene solution of $2.5 \mathrm{~mol} / \mathrm{l}$.

b Used as toluene solution of $1 \mathrm{~mol} / l$.

$[\eta]$ of copolymers measured in acetone at $30^{\circ} \mathrm{C}$ are 0.62 (c), 0.86 (d), 0.55 (e), and $0.46 \mathrm{~d} l / \mathrm{g}$ (f), respectively.

Table V. Copolymerization catalyzed by $\mathrm{EtAlCl}_{2}-\mathrm{VOCl}_{3}$ (A) or $\mathrm{EtAlCl}_{2}$ (B) system at $-78^{\circ} \mathrm{C}^{\text {a }}$

\begin{tabular}{|c|c|c|c|c|c|c|c|c|c|c|}
\hline \multicolumn{3}{|c|}{ Feed monomer } & \multicolumn{2}{|c|}{$\begin{array}{c}\mathrm{EtAlCl}_{2} \\
\mathrm{mmol}\end{array}$} & \multicolumn{2}{|c|}{$\begin{array}{c}\text { Polymerization } \\
\text { time }\end{array}$} & \multicolumn{2}{|c|}{ Polymer, $\mathrm{g}$} & \multicolumn{2}{|c|}{$\begin{array}{l}\text { AN content } \\
\text { in polymer, } \\
\text { mol } \%\end{array}$} \\
\hline $\begin{array}{l}\text { AN, } \\
\text { mmol }\end{array}$ & $\begin{array}{c}\mathrm{VC}, \\
\mathrm{mmol}\end{array}$ & $\begin{array}{c}\mathrm{AN} /(\mathrm{AN}+\mathrm{VC}), \\
\mathrm{mol} \%\end{array}$ & (A) & (B) & $\begin{array}{l}\text { (A), } \\
\text { day }\end{array}$ & $\begin{array}{l}\text { (B), } \\
\text { hr }\end{array}$ & (A) & (B) & (A) & (B) \\
\hline 10 & 190 & 5 & 10 & 10 & $6.5 \mathrm{hr}$ & 6.5 & $0.31_{9}$ & $0.10_{0}$ & 50 & 50 \\
\hline 20 & 180 & 10 & 10 & 20 & $6.5 \mathrm{hr}$ & 6.5 & $0.18_{2}^{\mathrm{b}}$ & $0.15_{1}$ & 55 & 50 \\
\hline 50 & 150 & 25 & 10 & 20 & $6.5 \mathrm{hr}$ & 6.5 & $0.06_{4}$ & $0.12_{5}$ & 60 & 58 \\
\hline 100 & 100 & 50 & 10 & 20 & 7 & 6.5 & $0.15_{5}$ & $0.07_{4}$ & 73 & 73 \\
\hline 150 & 50 & 75 & 10 & 20 & 7 & 6.5 & $0.12_{6}$ & $0.03_{0}$ & 82 & 84 \\
\hline 180 & 20 & 90 & 10 & 20 & 7 & 7 day & $0.06_{6}$ & $0.07_{2}$ & 95 & 95 \\
\hline 200 & 0 & 100 & 10 & - & 7 & - & $0.15_{9}$ & - & 100 & - \\
\hline
\end{tabular}

a Polymerization conditions: (A), $\left[\mathrm{VOCl}_{3}\right] /\left[\mathrm{EtAlCl}_{2}\right]$ in molar ratio $=0.2$, toluene, $3 \mathrm{~m} l ;(\mathrm{B})$, toluene $3 \mathrm{~m} l$.

${ }^{\mathrm{b}}[\eta]=0.33(\mathrm{~d} l / \mathrm{g})$, measured in acetone at $30^{\circ} \mathrm{C}$.

Table VI. Copolymerization catalyzed by $\mathrm{EtAlCl}_{2}-\mathrm{VOCl}_{3}$ (A) or $\mathrm{EtAlCl}_{2}$ (B) system at $-30^{\circ} \mathrm{C}$

\begin{tabular}{|c|c|c|c|c|c|c|c|c|c|c|}
\hline \multicolumn{3}{|c|}{ Feed monomer } & \multicolumn{2}{|c|}{$\underset{\text { mmol }}{\mathrm{EtAlCl}_{2}}$} & \multicolumn{2}{|c|}{$\begin{array}{l}\text { Polymerization } \\
\text { time, min }\end{array}$} & \multicolumn{2}{|c|}{$\begin{array}{c}\text { Polymer, } \\
\mathrm{g}\end{array}$} & \multicolumn{2}{|c|}{$\begin{array}{c}\text { AN content } \\
\text { in polymer, } \\
\text { mol } \%\end{array}$} \\
\hline $\begin{array}{l}\text { AN, } \\
\text { mmol }\end{array}$ & $\begin{array}{l}\mathrm{VC}, \\
\mathrm{mmol}\end{array}$ & $\begin{array}{c}\mathrm{AN} /(\mathrm{AN}+\mathrm{VC}) \\
\mathrm{mol} \%\end{array}$ & (A) & (B) & (A) & (B) & (A) & (B) & (A) & (B) \\
\hline 10 & 190 & 5 & 10 & 10 & 30 & - & $0.35_{5}$ & - & 52 & - \\
\hline 20 & 180 & 10 & 10 & 10 & 30 & 30 & $0.30^{5} \mathrm{~b}$ & $0.05_{6}$ & 56 & 55 \\
\hline 50 & 150 & 25 & 10 & 10 & 65 & 65 & $0.26_{6}$ & $0.06_{5}$ & 64 & 63 \\
\hline 100 & 100 & 50 & 10 & 10 & 240 & 240 & $0.51_{4}$ & $0.03_{7}$ & 73 & 76 \\
\hline 150 & 50 & 75 & 10 & 10 & 240 & 240 & $0.37_{8}$ & $0.01_{0}$ & 84 & - \\
\hline
\end{tabular}

a Polymerization conditions: (A), $\left[\mathrm{VOCl}_{3}\right] /\left[\mathrm{EtAlCl}_{2}\right]$ in molar ratio $=0.05$; toluene, $5 \mathrm{ml}$; (B), toluene, $5 \mathrm{ml}$.

${ }^{\mathrm{b}}[\eta]=0.23(\mathrm{~d} l / \mathrm{g})$, measured in acetone at $30^{\circ} \mathrm{C}$. 


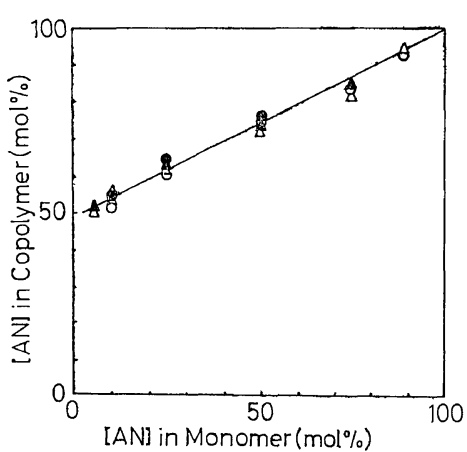

Figure 3. Copolymer composition curves by EtAlCl $2-\mathrm{VOCl}_{3}$ or EtAlCl${ }_{2}$; taken from Tables $\mathrm{V}$ and VI. [AN+VC], $200 \mathrm{mmol} ;\left[\mathrm{EtAlCl}_{2}\right] /[\mathrm{AN}+$ $\mathrm{VC}]$ in molar ratio, 0.05 ; $\triangle \mathrm{Et}_{\mathrm{AlCl}}-\mathrm{VOCl}_{3}$, $-78^{\circ} \mathrm{C}$; (A) $\mathrm{EtAlCl}_{2},-\mathrm{VOCl}_{3},-30^{\circ} \mathrm{C}$; (O) $\mathrm{EtAlCl}_{2},-78^{\circ} \mathrm{C} ;\left[\mathrm{EtAlCl}{ }_{2}\right] /[\mathrm{AN}+\mathrm{VC}]=0.10 ;$ $\mathrm{EtAlCl}_{2},-30^{\circ} \mathrm{C}$.

nating from the following facts.

(1) A 1:1-copolymer is always formed irrespective of the feed monomer composition.

(2) The copolymer having a 1:1-composition is completely soluble in acetone and its thermal stability is better than a $1: 1$-random copolymer prepared by a conventional radical initiator. This fact may be due to the absence of $\mathrm{AN}$ $\mathrm{AN}$ and $\mathrm{VC}-\mathrm{VC}$ dyad in the former copolymer.
Therefore, a film having good transparency can be formed by melt press.

(3) The dyad distribution in the copolymers is evaluated by the use of NMR spectra as shown in Figure 4 and Table VIII. The alternating copolymers(A and B) show absorptions at $4.24,3.15$ and $2.21 \mathrm{ppm}$ assignable to the methine proton of vinyl chloride and acrylonitrile units and the methylene proton of $\mathrm{AN}-$ VC dyad, respectively. This contrasts with the fact that both the radical copolymer(C) and the AN homopolymer(D) have the absorption at $2.07 \mathrm{ppm}$ assignable to the methylene proton of AN-AN dyad. Although the absence of a chemical shift of VC-VC dyad is not clear from the NMR spectra, it may be reasonably estimated from the fact that the copolymer of more than $50 \%$ in VC content is not obtained by these catalysts and the reactivity of vinyl chloride is much lower than that of AN monomer in the radical copolymerization. Therefore, the results of NMR spectra may prove that the copolymer obtained by an equimolar or more amount of organoaluminum halides with or without the transition metal compounds is alternating one.

On the other hand, in the case of $\mathrm{Al} / \mathrm{AN}<1$, the polymer composition deviates from a $(1: 1)$

Table VII. Copolymerization catalyzed by $\mathrm{EtAlCl}_{2}$-various transition metal compounds ${ }^{a}$

\begin{tabular}{|c|c|c|c|c|c|c|}
\hline \multirow{2}{*}{$\begin{array}{c}\mathrm{EtAlCl}_{2}{ }^{\mathrm{b}} \\
\mathrm{mmol}\end{array}$} & \multicolumn{2}{|c|}{ Transition metal } & \multirow{2}{*}{$\begin{array}{c}\text { Polymerization } \\
\text { temp, } \\
{ }^{\circ} \mathrm{C}\end{array}$} & \multirow{2}{*}{$\begin{array}{l}\text { Polymerization } \\
\text { time, } \\
\text { min }\end{array}$} & \multirow{2}{*}{$\underset{\mathrm{g}}{\text { Polymer, }}$} & \multirow{2}{*}{$\begin{array}{l}\text { AN content } \\
\text { in polymer, } \\
\text { mol } \%\end{array}$} \\
\hline & Compd, ${ }^{c}$ & $\mathrm{mmol}$ & & & & \\
\hline 5 & - & 0 & -30 & 240 & 0.02 & 76 \\
\hline 5 & $\mathrm{VOCl}_{3}$ & 0.25 & -30 & 240 & $0.25_{7}$ & 73 \\
\hline 12.5 & $\mathrm{VOCl}_{3}$ & 1.0 & -30 & 20 & $0.57_{8}$ & 73 \\
\hline 12.5 & $\mathrm{Co}(\mathrm{acac})_{3}{ }^{\mathrm{d}}$ & 1.0 & -30 & 30 & $0.60_{3}$ & 73 \\
\hline 12.5 & $\mathrm{TiCl}_{4}$ & 1.0 & -30 & 30 & $0.09_{6}$ & 74 \\
\hline 12.5 & $\begin{array}{l}\mathrm{TiCl}_{4}+\mathrm{Ti}(\mathrm{OnBu})_{4} \\
\quad(1: 1)\end{array}$ & 1.0 & -30 & 30 & $0.26_{4}$ & 72 \\
\hline 12.5 & $\mathrm{Fe}(\mathrm{acac})_{3}{ }^{\mathrm{d}}$ & 1.0 & -30 & 30 & $0.06_{3}$ & 74 \\
\hline 12.5 & $\mathrm{~V}(\mathrm{acac})_{3}{ }^{\mathrm{d}}$ & 1.0 & -30 & 30 & $0.32_{8}$ & 74 \\
\hline 2.5 & - & 0 & -15 & 4 day & 0.04 & 74 \\
\hline 2.5 & $\mathrm{VOCl}_{3}$ & 0.5 & -15 & 4 day & 1.07 & 73 \\
\hline 2.5 & $\mathrm{VO}(\mathrm{OEt})_{3}$ & 0.5 & -15 & 4 day & 0.99 & 73 \\
\hline
\end{tabular}

a Polymerization conditions: [AN], $50 \mathrm{mmol}$; [VC], $50 \mathrm{mmol}$; solvent, toluene $10 \mathrm{ml}$.

b Used as toluene solution of $2.5 \mathrm{~mol} / l$.

c Used as toluene solution of $1.0 \mathrm{~mol} / l$.

d (acac) indicates acetylacetonate. 


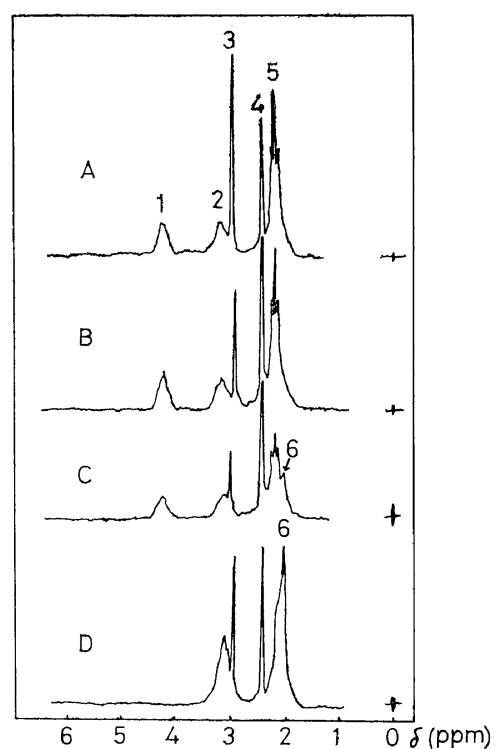

Figure 4. NMR spectra of AN-VC copolymer:

(A) Alternating copolymer prepared by $\mathrm{EtAlCl}_{2}$ $-\mathrm{VOCl}_{3}$,

(B) Alternating copolymer prepared by $\mathrm{EtAlCl}_{2}$,

(C) Random copolymer of 1:1-composition prepared by $\mathrm{BPO}$ at $60^{\circ} \mathrm{C}$,

(D) Homopolymer of acrylonitrile prepared by $\mathrm{EtAlCl}_{2}-\mathrm{VOCl}_{3}$.

Table VIII. Assignment of NMR spectra of $\mathrm{AN}-\mathrm{VC}$ copolymers

\begin{tabular}{|c|c|c|}
\hline No. & $\begin{array}{l}\text { Chemical shift } \\
\delta, \text { ppm }\end{array}$ & Assignment \\
\hline 1 & 4.24 & $\underline{\mathrm{H}}-\mathrm{C}-\mathrm{Cl}$ \\
\hline 2 & 3.15 & $\mathrm{H}-\mathrm{C}-\mathrm{CN}$ \\
\hline 3 & 2.91 & water \\
\hline 4 & 2.44 & solvent \\
\hline 5 & 2.21 & $-\underset{\mid}{\mathrm{CH}}-\underline{\mathrm{CH}}_{2}-\underset{\mid}{\mathrm{CH}}-$ \\
\hline 6 & 2.07 & $-\underset{\mid}{\mathrm{CH}}-\mathrm{CH}_{2}-\underset{\mid}{\mathrm{CH}}-$ \\
\hline
\end{tabular}

and the AN-rich copolymer is formed. The copolymer is found to be homogeneous but not a mixture of alternating and AN-homopolymer from the fractionation result of the copolymer.
An example of the fractionation is as follows: the copolymer prepared by the polymerization of the 1:1-monomer mixture with $\mathrm{EtAlCl}_{2}$ ( $2.5 \mathrm{~mol} \%$ of total monomer), was fractionated into acetone-soluble and -insoluble parts, whose weight amounts are 42 and $58 \%$, respectively. AN contents were found to be almost the same, i.e., $73 \mathrm{~mol} \%$ for the soluble part and $75 \mathrm{~mol} \%$ for the insoluble part.

A characteristic feature of this sort of polymerization is the formation of the AN-rich copolymer when an insufficient amount of aluminum compound is used. This may be accounted for by the participation of the free or complexed AN-monomer, or the elimination of $\mathrm{VC}$ monomer during copolymerization. It was known that acrylonitrile is complexed with $\mathrm{EtAlCl}_{2} \quad$ completely, but the complexed ANmonomer does not exhibit activity in the homopolymerization. In the alternating copolymerization of acrylonitrile with butadiene, both free and complexed acrylonitriles do not participate in the copolymerization, ${ }^{13}$ but the copolymerizability of AN monomer or its complex with vinyl chloride is not necessarily the same as that with butadiene. As another possibility the polymerization is accompanied by the elimination reaction of vinyl chloride monomer from the polymer terminal similar to the copolymerization of styrene and sulfur dioxide involving the elimination of styrene. ${ }^{14}$ These possibilities can be checked by the kinetic measurement of copolymer composition as follows.

The case with the participation of free ANmonomer is regarded as a copolymerization of the free $\mathrm{AN}$ and the $\mathrm{VC}-\mathrm{AN}-\mathrm{Al}$ complexed monomer. The monomer consumption or the polymer composition is represented by eq 1 .

$$
\begin{aligned}
\frac{\mathrm{d}[\mathrm{AN}]}{\mathrm{d}[\mathrm{VC}]} & =\frac{\mathrm{d}[\mathrm{AN}]_{\mathrm{f}}+\mathrm{d}[\mathrm{VC} \cdot \mathrm{AN} \cdot \mathrm{Al}]}{\mathrm{d}[\mathrm{VC} \cdot \mathrm{AN} \cdot \mathrm{Al}]} \\
& =1+\frac{\mathrm{d}[\mathrm{AN}]_{\mathrm{f}}}{\mathrm{d}[\mathrm{VC} \cdot \mathrm{AN} \cdot \mathrm{Al}]}
\end{aligned}
$$

Here, $[\mathrm{AN}]_{\mathrm{f}}$ is the concentration of the free AN-monomer and in the case of complete complexation, it is expressed as eq 2 .

$$
[\mathrm{AN}]_{\mathrm{f}}=[\mathrm{AN}]-[\mathrm{Al}]
$$

If $[\mathrm{AN}] \leqq[\mathrm{Al}]$, eq 3 is applied instead of eq 2 .

$$
[\mathrm{AN}]_{\mathrm{f}}=0
$$




\section{J. Furukawa, H. Kobayashi, and J. Yamauchi}

and then

$$
\frac{\mathrm{d}[\mathrm{AN}]}{\mathrm{d}[\mathrm{VC}]}=1
$$

If $[\mathrm{AN}]>[\mathrm{Al}]$, the monomer consumption ratio is expressed as the combination of eq 1 and 5 .

$$
\begin{aligned}
& \frac{\mathrm{d}[\mathrm{AN}]_{\mathrm{f}}}{\mathrm{d}[\mathrm{VC} \cdot \mathrm{AN} \cdot \mathrm{Al}]} \\
& \quad=\frac{[\mathrm{AN}]_{\mathrm{f}}}{[\mathrm{VC} \cdot \mathrm{AN} \cdot \mathrm{Al}]} \frac{r_{1}[\mathrm{AN}]_{\mathrm{f}}+[\mathrm{VC} \cdot \mathrm{AN} \cdot \mathrm{Al}]}{[\mathrm{AN}]_{\mathrm{f}}+r_{2}[\mathrm{VC} \cdot \mathrm{AN} \cdot \mathrm{Al}]}
\end{aligned}
$$

For the sake of simplicity, it is assumed that

$$
\frac{\mathrm{d}[\mathrm{AN}]_{\mathrm{f}}}{\mathrm{d}[\mathrm{VC} \cdot \mathrm{AN} \cdot \mathrm{Al}]}=r \frac{[\mathrm{AN}]_{\mathrm{f}}}{[\mathrm{VC} \cdot \mathrm{AN} \cdot \mathrm{Al}]}
$$

where $r$ is $r_{1}$ or $1 / r_{2}$ depending on the condition that $r_{1} \gg 1$ and $r_{2} \ll 1$, or $r_{1} \ll 1$ and $r_{2} \gg 1$, respectively,

The VC-AN-Al complex may be expressed in an equation to that of the $\mathrm{BD}-\mathrm{AN}-\mathrm{Al}$ complex, ${ }^{13}$ i.e.,

$$
[\mathrm{VC} \cdot \mathrm{AN} \cdot \mathrm{Al}]=\frac{K_{2}[\mathrm{Al}][\mathrm{AN}][\mathrm{VC}]}{1+K_{1}[\mathrm{AN}]^{n}+K_{2}[\mathrm{AN}][\mathrm{VC}]}
$$

Similarly to the $\mathrm{BD}-\mathrm{AN}-\mathrm{Al}$ complex, it is assumed that $K_{1} \gg K_{2}, 1$ and $n$ is $2,{ }^{12}$ and hence

$$
[\mathrm{VC} \cdot \mathrm{AN} \cdot \mathrm{Al}]=\frac{K_{2}[\mathrm{Al}][\mathrm{VC}]}{K_{1}[\mathrm{AN}]}
$$

Substituting eq 2, 6, and 8 into eq 1 , it follows that

$$
\frac{\mathrm{d}[\mathrm{AN}]}{\mathrm{d}[\mathrm{VC}]}=1+\left(r \frac{K_{1}}{K_{2}}\right)\left(\frac{[\mathrm{AN}]-[\mathrm{Al}]}{[\mathrm{Al}]}\right)\left(\frac{[\mathrm{AN}]}{[\mathrm{VC}]}\right)
$$

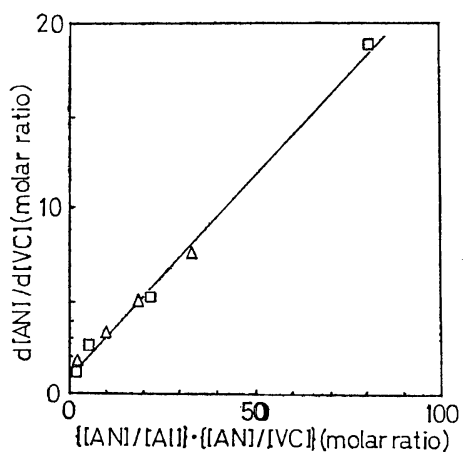

Figure 5. Relation of d[AN]/d[VC] to ([AN]/[Al] $) \times$ ([AN]/[VC]) in copolymerization; taken from Figure 1.

$[\mathrm{AN}+\mathrm{VC}] /[\mathrm{Al}]$ in molar ratio: $\triangle, 4 ; \square, 20$.

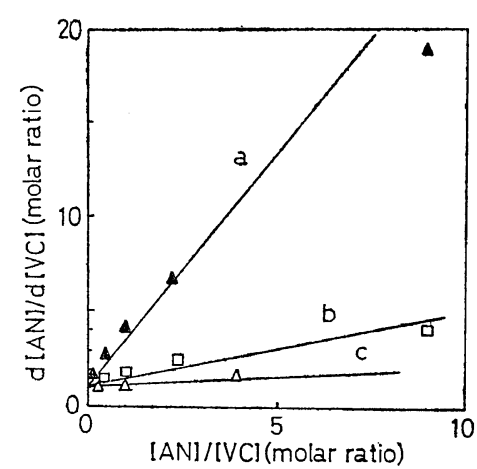

Figure 6. Relation of $\mathrm{d}[\mathrm{AN}] / \mathrm{d}[\mathrm{VC}]$ to $[\mathrm{AN}] /[\mathrm{VC}]$ in copolymerization; taken from Figure 2.

[AN]/[Al] in molar ratio: a, $10 ; \mathrm{b}, 2 ; \mathrm{c}, 1.33$.

If $[\mathrm{AN}] \gg[\mathrm{Al}],[(\mathrm{AN}] /[\mathrm{Al}])-1]$ is nearly equal to $[\mathrm{AN}] /[\mathrm{Al}]$. The experimental results fit eq 9 as shown in Figures 5 and 6 , from which $r K_{1} / K_{2}$ is estimated to be $0.25-0.22$. Since $K_{1}$ is larger than $K_{2}$, in the AN-VC copolymerization, $r$ is less than unity and and therefore $r=1 / r_{2}$ and $r_{2}>$ 1. Therefore, free AN-monomer is not so active in the case of the $\mathrm{VC}-\mathrm{AN}-\mathrm{EtAlCl}_{2}$ copolymerization.

The participation of AN-Al complexed monomer is expressed by the following copolymerization equation instead of eq 9 ,

$$
\begin{aligned}
\frac{\mathrm{d}[\mathrm{AN}]}{\mathrm{d}[\mathrm{VC}]} & =1+\left(r \frac{K_{1}}{K_{2}}\right) \frac{[\mathrm{Al}][\mathrm{AN}]^{n}}{[\mathrm{Al}][\mathrm{AN}][\mathrm{VC}]} \\
& =1+\left(r \frac{K_{1}}{K_{2}}\right) \frac{[\mathrm{AN}]^{n-1}}{[\mathrm{VC}]}
\end{aligned}
$$

A similar equation has been proposed by Barb for ethylene-CO copolymerization. ${ }^{15}$ This equation involves no dependency of aluminum compound on copolymerization contrary to the result of the experiments.

The path involving the elimination of VCmonomer from the growing chain-end can be expressed as follows

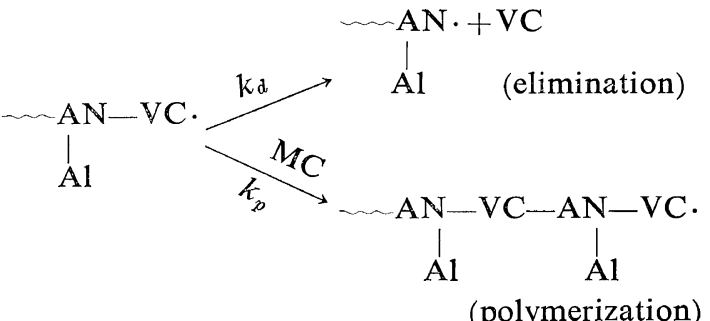

Polymer J., Vol. 2, No. 3, 1971 
where $\mathrm{MC}$ and $\left[\mathrm{M}^{*}\right]$ denote the concentration of $\mathrm{VC}-\mathrm{AN}-\mathrm{Al}$ complex in the above scheme and that of active end, respectively. In this case it follows that

$$
\begin{aligned}
\frac{\mathrm{d}[\mathrm{VC}]}{\mathrm{d}[\mathrm{AN}]} & =\frac{\mathrm{d}[\mathrm{VC} \cdot \mathrm{AN} \cdot \mathrm{Al}]-\mathrm{d}[\mathrm{VC}]_{\mathrm{elim}}}{\mathrm{d}[\mathrm{VC} \cdot \mathrm{AN} \cdot \mathrm{Al}]} \\
& =1-\frac{\mathrm{d}[\mathrm{VC}]_{\ominus 1 \mathrm{im}}}{\mathrm{d}[\mathrm{VC} \cdot \mathrm{AN} \cdot \mathrm{Al}]}=1-\frac{k_{d}\left[\mathrm{M}^{*}\right]}{k_{p}\left[\mathrm{M}^{*}\right][\mathrm{MC}]} \\
& =1-\frac{k_{d} K_{1}[\mathrm{AN}]^{n-1}}{k_{p} K_{2}[\mathrm{Al}][\mathrm{VC}]}
\end{aligned}
$$

Eq 11 does not agree with experimental data as illustrated in Figure 7 or 8 in either case that $n$ is $2^{12}$ or $3{ }^{13}$ respectively. Moreover, eq 11 is not sufficient to account for the fact that the complete alternating copolymer can be formed in the presence of more than an equimolar amount of aluminum compound. The reason for the difference between $\mathrm{AN}-\mathrm{VC}$ and AN-BD copolymerization is not yet elucidated. The excess incorporation of AN mono-

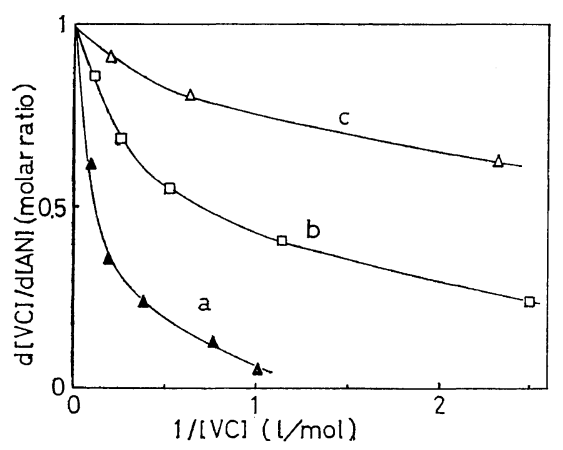

Figure 7. Plots of $d[\mathrm{VC}] / \mathrm{d}[\mathrm{AN}]$ to $1 /[\mathrm{VC}]$ in copolymerization; taken from Figure 2.

[AN]/[Al] in molar ratio: a, 10; b, 2; c, 1.33.

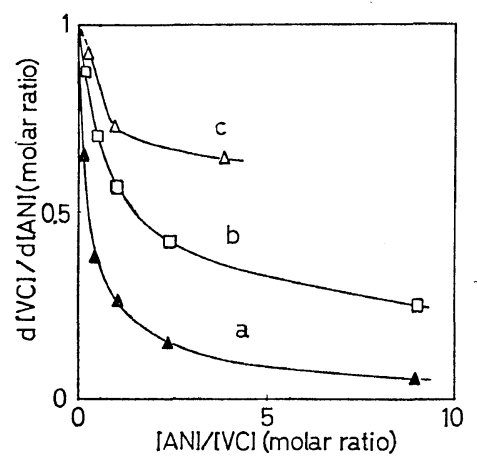

Figure 8. Plots of $d[\mathrm{VC}] / \mathrm{d}[\mathrm{AN}]$ to $[\mathrm{AN}] /[\mathrm{VC}]$ in copolymerization; taken from Figure 2. [AN]/[Al] in molar ratio: a, 10; b, 2; c, 1.33. mer in the case of AN-VC-complex system may be ascribed to the low activity of $\mathrm{AN}-\mathrm{VC}$ complex during the copolymerization or to the low degree of the complex formation in comparison with the $\mathrm{AN}-\mathrm{BD}$-complex system.

Finally, a simple copolymerization of complexed-AN monomer and vinyl chloride is to be taken into consideration for the alternating copolymerization, since the polar nature of acrylonitrile is much enhanced by the complexation with $\mathrm{EtAlCl}_{2}$ possibly with sufficiency to conduct the alternating copolymerization with vinyl chloride monomer. This problem will be discussed in a further report.

Acknowledgments. We wish to thank Mr. S. Takashima for elemental analysis and $\mathrm{Mr}$ I. Kuruma for NMR measurements.

\section{REFERENCES}

1. M. Imoto, T. Ohtsu, and Y. Harada, Makromol. Chem., 65, 180 (1963).

2. M. Hirooka, H. Yabuuchi, S. Morita, S. Kawasumi, and K. Nakaguchi, J. Polym. Sci., Part $B, 5,47$ (1967).

3. N. G. Gaylord and A. Takahashi, J. Polym. Sci., Part B, 6, 749 (1968).

4. J. Furukawa and Y. Iseda, J. Polym. Sci., Part $B, 7,47$ (1969); J. Furukawa, Y. Iseda, K. Haga, and N. Kataoka, J. Polym. Sci., Part A-1, 8, 1147 (1970).

5. N. G. Gaylord and A. Takahashi, Paper presented at the Annual Meeting of the American Chemical Society, San Francisco, Calif., 1968.

6. K. Nakaguchi, S. Kawasumi, M. Hirooka, and H. Yabuuchi, Japanese Patent 1968-625 (1968).

7. S. Pasynkiewicz, W. Kuran, and T. Diem, $J$. Polym. Sci., Part A-1, 7, 2411 (1969).

8. Y. Takeuchi and M. Ichikawa, Preprint, SPSJ 16th Symposium on Macromolecules, Fukuoka, October, 1967, p 470.

9. S. Pasynkiewicz, W. Kuran, and T. Diem, $J$. Organometal. Chem., 15, 307 (1968).

10. K. Nambu, Kobunshi Kagaku (Chem. High Polymers), 20, 113 (1963).

11. J. Furukawa, E. Kobayashi, and Y. Iseda, Polymer J., 1, 155 (1970).

12. J. Furukawa, Y. Iseda, and E. Kobayashi, $J$. Polym. Sci., Part B, 8, 631 (1970).

13. J. Furukawa, E. Kobayashi, Y. Iseda, and Y. Arai, Polymer J., 1, 442 (1970).

14. W. G. Barb, Proc. Royal Soc., A, 212, 66 (1952).

15. W. G. Barb, J. Amer. Chem. Soc., 75, 224 (1953). 